
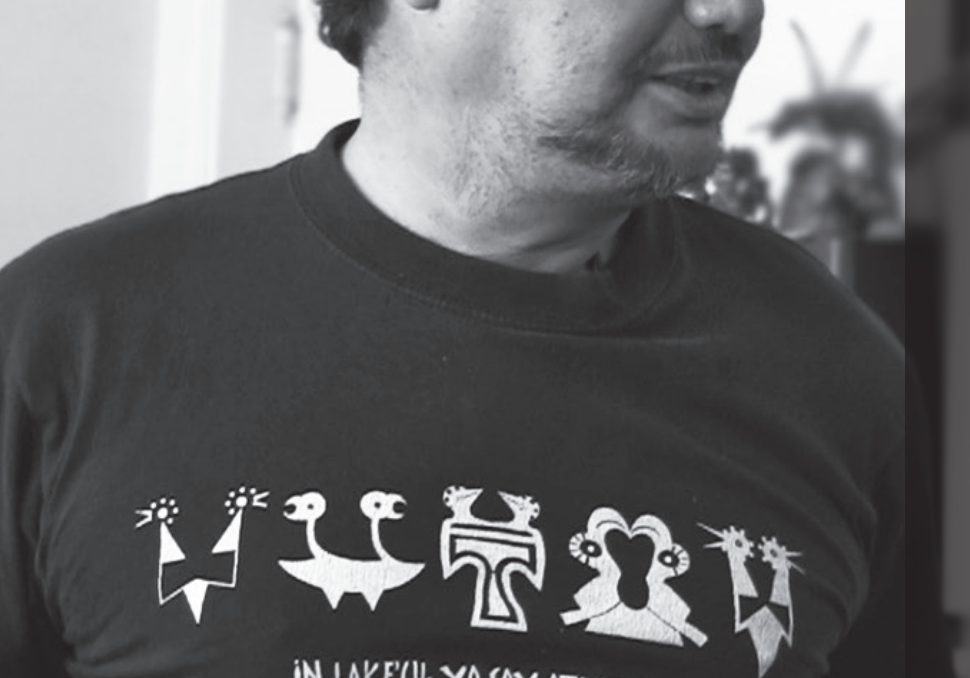

IN LAKE'(H: YO SOY OTOO TU

\section{CARLOS HENAO: SOBRE LA ESCRITURA EN EL DOCUMENTAL Y EN LA FICCIÓN}

\section{CARLOS HENAO: ABOUT WRITING IN THE DOCUMENTARY AND FICTION \\ CARLOS HIENA: \\ DOCUMENTARY AND FICTION}

Resumen: Esta entrevista con el guionista, profesor y asesor en escritura de guión Carlos Henao, aborda distintos aspectos asociados a la escritura en el cine. La entrevista incursiona en temas como las relaciones entre la escritura en la ficción y el documental; la metodología de trabajo en la escritura de guiones en Víctor Gaviria, quien parte de situaciones relatadas por su propios protagonistas; y la visión de Henao sobre algunas variaciones registradas en el cine de ficción colombiano en la última década.

Palabras Clave: Documental, ficción, guión, poética, representación, relato, retórica.

Abstract: This interview with the writer, teacher and consultant in screenwriting Carlos Henao, addresses several issues associated with writing on films. The interview ventures into topics such as the relationship between writing in fiction and documentaries; methodology of work in screenwriting with Victor Gaviria, who recounted part of his protagonists situations; and the Henao's vision on some recorded variations in Colombian fiction films of the last decade.

Keywords: Documentary, fiction, screenwriting, poetry, representation, narrative, rhetoric. 


\section{Introducción}

Carlos Henao es guionista, asistente de dirección, asesor en la escritura de guiones y crítico de cine. Sus guiones tienen como rasgo particular un fuerte vínculo con la realidad y un espíritu documentalista. Carlos Henao es coguionista de La vendedora de rosas (1998) y La sangre y la lluvia (2009). Es miembro fundador de la Asociación de Guionistas Colombianos y Director Académico de la Corporación Cinefilia.

Esta entrevista se realizó en el desarrollo del proyecto de investigación Documental de creación. Voces, ideas, imágenes, que cuenta con el apoyo de la Vicerrecetoría de Investigaciones de la Universidad del Valle. El proyecto surgió como una extensión del Diplomado Internacional de Documental de Creación de la Escuela de Comunicación de la Universidad del Valle. Su propósito central es brindar un panorama de voces y conceptos acerca de la actualidad y la tradición del documental, con miradas y testimonios que hacen referencia al contexto nacional e internacional. Durante la entrevista con Carlos Henao también estuvo presente la investigadora Isabel Otálvaro, docente de la Corporación Cinefilia.

Manuel Silva: Hablemos de escrituras, puede ser interesante la relación que establezcas entre la escritura en la ficción y en el documental. Podemos considerar, por ejemplo, los trabajos que has hecho con Víctor Gaviria. En términos de investigación, ¿cuáles han sido los procesos, las búsquedas retóricas o dramatúrgicas?

Carlos Henao: En cierto sentido, cualquier relato, hablo de relato para referirme tanto al documental como a la ficción, surge en una inspiración. En el caso de mi relación con Víctor como coguionista de sus películas, hay una inspiración muy fuerte en la realidad, tratar de convertir situaciones, episodios, anécdotas, experiencias vividas, en historias de ficción. Eso explica una cosa muy importante antes de pensar, de sentarse a escribir o de imaginarse una historia: tener claro cuál es el tipo de cine que uno quiere hacer. A veces la gente se acerca al proceso de la escritura sin tenerlo claro. Es muy importante esa claridad. Víctor ha sido claro en el tipo de cine que quiere hacer y ahí he coincidido yo también.

A veces esas historias se alimentan de la realidad. Otras, películas como Simón el mago (1992) o La vendedora de rosas (1998) han tomado como punto de partida relatos literarios que luego se han nutrido de la realidad, porque ese es el espíritu que las nutre. En ese sentido, películas como La vendedora de rosas se confunden, como que es más documental que ficción. Nosotros hemos tenido algo, un espíritu documentalista que te alimenta a la hora de construir una ficción. En ese proceso ha servido saber que si uno quiere hacer un cine con ese espíritu realista es muy importante la investigación. En el fondo, el problema que tendría un realizador documentalista o uno de ficción es enfrentarse a la representación. La representación implica tener una mirada, una visión, tener claro cuál es el cine que querés hacer. 
MS: ¿Cómo definirías representación?

CH: El hecho de que el cine históricamente nunca se ha podido separar de algo que viene de otras artes, que es lo mimético. El asunto de la mímesis, de tener consciencia de la presencia de la cámara, va a generar que se esté buscando imitar, representar, poner en escena frente a ella esos elementos que pueden estar inspirados en la vida. O que son la vida misma, pero que inevitablemente tienen que pasar por ese filtro, por esa interpretación y esa subjetividad de quien mira.

Isabel Otálvaro: En las películas de Víctor, siendo de ficción, el método de escritura está ligado a técnicas más cercanas al documental. Hay mucho trabajo de entrevistas, con el contexto que quiere representar la película. La escritura se hace sobre la marcha con las personas, no es tanto que el autor se sienta a inspirarse y a escribir una obra. El documental se escribe así, sobre la marcha.

CH: Sí, pero, por ejemplo, a veces cuando vos hacés un retrato a esa persona la registra la cámara en un tiempo y un espacio determinados. Uno puede encontrar documentales que utilizan una estructura cercana a la ficción en la medida en que a través del montaje, del tema y de la selección del retrato del personaje parten de una premisa, que funciona tanto en el documental como en la ficción. La premisa es que una persona siempre está buscando algo. Las acciones, sean ficción o documentales, se dan sobre necesidades, están ligadas a un aquí y un ahora en el que las personas están buscando ser o hacer. En ese sentido, películas como La vendedora de rosas, Sumas y restas (2004) o aun Simón el mago se relacionan con el cine mismo, y relacionarse con el cine mismo está ligado a un concepto de tiempo y espacio. Inevitablemente tenés que ordenar el tiempo. El tiempo de los personajes, en la ficción o en el documental, lo ordenás a través de esa cosa esencial en el cine que es el montaje.

Cuando pensamos en una película pensamos en ordenar el tiempo de los personajes. Como relato, las películas tienen un límite que no tiene la vida, aunque el límite de la vida es la muerte. En ese sentido, las películas sí se construyen con una estructura de ficción. Para mí la ficción privilegia los sentimientos y las emociones de los personajes, cómo un personaje está buscando algo y eso lo afecta emocionalmente. Puede que algunos documentales traten de eso, pero no es una cosa muy clara. En la ficción tienes un personaje, seleccionas una necesidad de él, construyes una historia que transcurra en un tiempo y en un espacio determinado y, obviamente, entran la imaginación, la manipulación, lo selectivo. Por ejemplo, en La vendedora de rosas el relato tenía un tiempo: eran 48 horas en la vida de las niñas, el objetivo y la necesidad de Mónica era estar en la navidad con su abuela. Ese deseo inconsciente de ella se manifestaba a través de una serie de acciones que hacían consciente esa necesidad de afecto. Eso es ficción, porque para Leidy Tabares, que interpretaba a Mónica Rodríguez, esa no era su necesidad, no era su emoción desde el punto de vista de su vida, de la realidad. El asunto de la representación es cómo alimentamos esa ficción de la vida misma y tratamos de tener una fidelidad al entorno. Entonces, el problema que tiene que resolver un director es cómo represento, cómo mi personaje expresa lo que siente. En ese cómo está un poco la fidelidad a la realidad. 
CH: El concepto de verdad está ligado a que vos en este momento me estás registrando a través de la cámara, y lo que registra la cámara es lo que yo opino de lo que estamos hablando. Pero, ¿dónde está mi pensamiento ligado a la emoción? Entonces, el cine explora en la ficción cosas que también explora en el documental, pero en la ficción a veces ciertos realizadores las privilegian. Poder hablar de los verdaderos sentimientos humanos, como cuando un actor encarna un personaje que es una idea de persona, no es una persona, esa idea de persona permite expresar y a la cámara meterse en los momentos de intimidad. Esos momentos permiten una exploración de los sentimientos, y yo hablaría de los verdaderos sentimientos. Hablar de esos sentimientos a través de la ficción es como que la cámara puede estar registrando una apariencia, pero lo que de pronto puede explorarse a través de la ficción es una esencia ligada a los sentimientos. Cuando hablo de verdad hablo un poco de eso. En Viaje en Italia (1954) de Roberto Rossellini uno ve que la pareja protagonista está constantemente en discusiones, que está en crisis. A través del viaje uno se da cuenta que la manera como Rossellini filma esta pareja no está solamente en la apariencia de la representación, sino a través de un elemento que exploran ciertas películas estilísticamente, del subtexto, en el que uno va descubriendo la verdad de ellos.

Hay momentos de incomunicación entre ellos, muchas cosas no se entiendan, pero todo eso es una manifestación de algo que está dentro de la relación. Y la película termina de una manera muy simbólica, porque en el fondo, a pesar de todo, ellos se dan cuenta de que se quieren. Entonces, ¿qué hay de documental y qué hay de ficción ahí, cuando la película puede estar inspirada en los momentos críticos que Rossellini tenía con su pareja, Ingrid Bergman? Pero también, ¿qué permite la ficción?

MS: En La Retórica Aristóteles distingue entre logos, pathos y ethos. Y en la manera en la que tú tomas una postura sobre la ficción en relación con el documental veo que pones unos elementos del lado de la ficción y otros del lado del documental. Pero podemos encontrar que el pathos y el ethos también tienen una función muy fuerte en el documental, más aún en el contemporáneo.

CH: Sí, claro. Hay un documental hecho en el espíritu de los talleres Varán, que hizo Catalina Villar en Medellín, en el que registra a unos estudiantes de último año de secundaria [Diario de Medellín, 1998]. En él, el profesor de literatura les pone como ejercicio a los estudiantes que escriban un diario y Catalina va explorando con algunos alumnos el proceso de la escritura, cómo es la relación de su vida cotidiana. En ese proceso el documental se encontró con un personaje que es invitado a Roma a conocer al Papa porque hace parte de un grupo cristiano. Ella seleccionó a este personaje y empezó a seguir su expectativa del viaje. Una cosa que afloraba como una verdad en el personaje es que él necesitaba el permiso de su padre para poder salir del país, porque era menor de edad.Y él hacía muchos años no veía a su padre, ni siquiera sabía dónde estaba. Entonces emprendió un trabajo de investigación y de peregrinación en lugares en Medellín para encontrarlo, para que le firmara la autorización para poder salir. Esto sucedió en la realidad, lo registró Catalina, pero la manera como ella lo ordenó en el montaje daba la sensación de que fuese una película de ficción. 
En ese sentido, uno podría encontrar que el concepto aristotélico de la dramaturgia no es un asunto que haya inventado Aristóteles, sino que es más una correspondencia con una observación de la vida. En nuestra vida cotidiana nos movemos permanentemente sobre objetivos, sobre necesidades. Alguien me decía que el cine de ficción es muy conductista porque las historias se ordenan en función de que un personaje tiene un objetivo y eso permite generar una estructura que puede pasar por un planteamiento, un desarrollo y un desenlace. Lo que privilegia la dramaturgia, a diferencia del documental, aunque hay documentales que sí lo buscan, no porque estén haciendo ficción sino porque es parte de la realidad misma, es la presencia de conflicto. Es decir, que un ser humano no solamente tiene un objetivo, sino que interactúa con otras personas y siempre va a encontrar obstáculos frente a sus necesidades, frente a su objetivo. Eso no lo inventó Aristóteles, la vida misma es así, por eso ponía el ejemplo de Catalina. Hay directores a quienes les interesa, tanto en el documental como en la ficción, explorar y relacionar al sujeto o a la persona que filman con esa premisa.

MS: Hay quienes ponen en cuestión la relación ficción-no ficción porque leen lo que tú señalas de una manera contraria. Cuando muere un personaje en la ficción murió el personaje, no el actor. Cuando veo en De(s)amparo (2002), de Gustavo Fernández, que su hermano interviene en el comienzo pero no termina porque tuvo un accidente, no es un actor el que ha actuado una muerte, murió la persona. Esto ha llevado a que en términos de la relación empática se marquen diferencias.

$\mathbf{C H}$ : Te pongo un ejemplo que me llevó a entender eso. Una vez estaba con un amigo escribiendo un guión. De casualidad llegó otro amigo a hacernos la visita. Diez minutos más tarde llegó una amiga con su novio. Yo sabía que el amigo que había llegado a hacernos la visita era amante de mi amiga, lo cual no sabía el novio. En apariencia, la conversación fue trivial, todo funcionó muy bien. Mi amiga hizo una actuación extraordinaria, no se puso nerviosa, fue muy cariñosa con su novio, su novio creó una empatía con el amante. Yo sabía la verdad, sabía verdaderamente qué estaban sintiendo mi amiga y mi amigo. Después lo constataron en una conversación. Al otro, con el que estaba escribiendo, le parecía que todo funcionaba perfecto. Si yo hubiera filmado esa reunión la cámara hubiera registrado esa aparente realidad. Pero la verdad, si me meto en el sujeto, si me meto en ella o en él, era lo que por dentro estaban sintiendo y pensando, que no tenía nada que ver con lo que hubiera registrado la cámara.

Para mí ese concepto de verdad está ligado a que cada ser humano tiene en su interior una complejidad de existencia, siempre nos relacionamos en nuestras vidas cotidianas con la máscara. Lo que me parece interesante con la ficción es que podemos jugar a una representación que se queda en esa realidad para poder quitarnos esa máscara. Cuando uno entra en la ficción explora los verdaderos sentimientos de alguien que se está quitando la máscara de la apariencia. Eso es lo que veo e interpreto, no la verdad filosófica, ni existencial. Es cómo el cine a través de la ficción, y obviamente el documental lo logra también, puede ir quitando esa máscara que a veces somos los seres humanos.

MS: Por otra parte, la escritura puede estar pensada de manera restringida alrededor del guión, pero la concepción de escritura trasciende eso. Hablo del montaje, por ejemplo. 
CH: Totalmente de acuerdo. Desde la industria del cine se ha mitificado el guión, hay una sobrevaloración. La realización de una película es un proceso creativo que acaba en el momento en el que vos cerrás definitivamente el montaje y el diseño sonoro, etc. El proceso creativo no se agota en el guión ni en el rodaje, empieza a surgir en el montaje mismo. Es más adecuado hablar de escritura no para referirse a la literalidad de la redacción de un guión, sino al proceso. El concepto de escritura implica estar abierto en todas las fases del proceso creativo de la película. Hay unas constantes que surgen en el guión, pero lo más importante que uno podría hacer es privilegiar la inspiración, y la inspiración no se cierra en la escritura literal del guión.

MS: Te atreverías a señalar alguna singularidad en la escritura para la ficción y la no ficción.

CH: Es un asunto de la mirada, de tener claro qué es lo que uno como autor o el documentalista quiera expresar y cómo lo quiera expresar. A veces el documental permite expresar algunas cosas que probablemente en la ficción no tendrían el mismo sentido, el mismo efecto. En un documental reciente de Herzog, que gira en torno a un condenado a muerte en Estados Unidos, uno ve que la fuerza está dada precisamente por el ejemplo que vos dabas, que, como decía Cocteau citado por Godard, el cine es el único arte que filma el trabajo de la muerte. En este documental, uno diría "esto no lo va a reemplazar una película de ficción".

MS: En Colombia se ha incrementado el número de películas aproximadamente en los últimos 10 años. Si miras hacia atrás, hacia la época de Focine, ¿han evolucionado las escrituras, tanto en ficción como en documental?

CH: Sí. Eso está ligado a una coincidencia de lo que ha pasado en los últimos 10 años con la imagen audiovisual y es lo que ha posibilitado el cine digital. La calidad de la imagen que registran las cámaras permite no tenerle miedo a ese recurso. Este año, el 2012, para mí es uno de los más importantes en el cine colombiano. Valoro mucho el cine que ese está haciendo, lo valoro en términos cualitativos, no en términos cuantitativos. Siento que hay una tendencia a valorar más el cine colombiano en términos de cantidad que en calidad, y cuando hablo del cine colombiano hablo también del documental. Siento que está surgiendo una generación de jóvenes cineastas que están arriesgando y están generando una serie de películas van en el espíritu de relacionarse con el cine como una expresión artística, que permitan llegar a unas profundidades del conocimiento y de la representación de los seres humanos, del ser colombiano. Hablo de películas como Porfirio (2011), La sirga (2012) o La playa (2012), que representan un nivel de calidad extraordinario. No es casual que este año La playa y La sirga hayan estado en un festival de cine tan importante como el de Cannes. Hay películas que trascienden y trasgreden una relación de complicidad o de condescendencia con el espectador colombiano.

Si lo valoramos en términos cuantitativos, se genera también una serie de películas que hacen parte de la industria. Eso lo vas a encontrar en todas las cinematografías del mundo: películas de entretenimiento, de género, que le apuestan a otra mirada. Lo traumático es que en esas películas uno no encuentra calidad, en ellas debería también haber calidad. No es anteponer una película de arte y ensayo a una comercial. En las películas comerciales es muy importante que haya calidad, que haya una mirada interesante. 


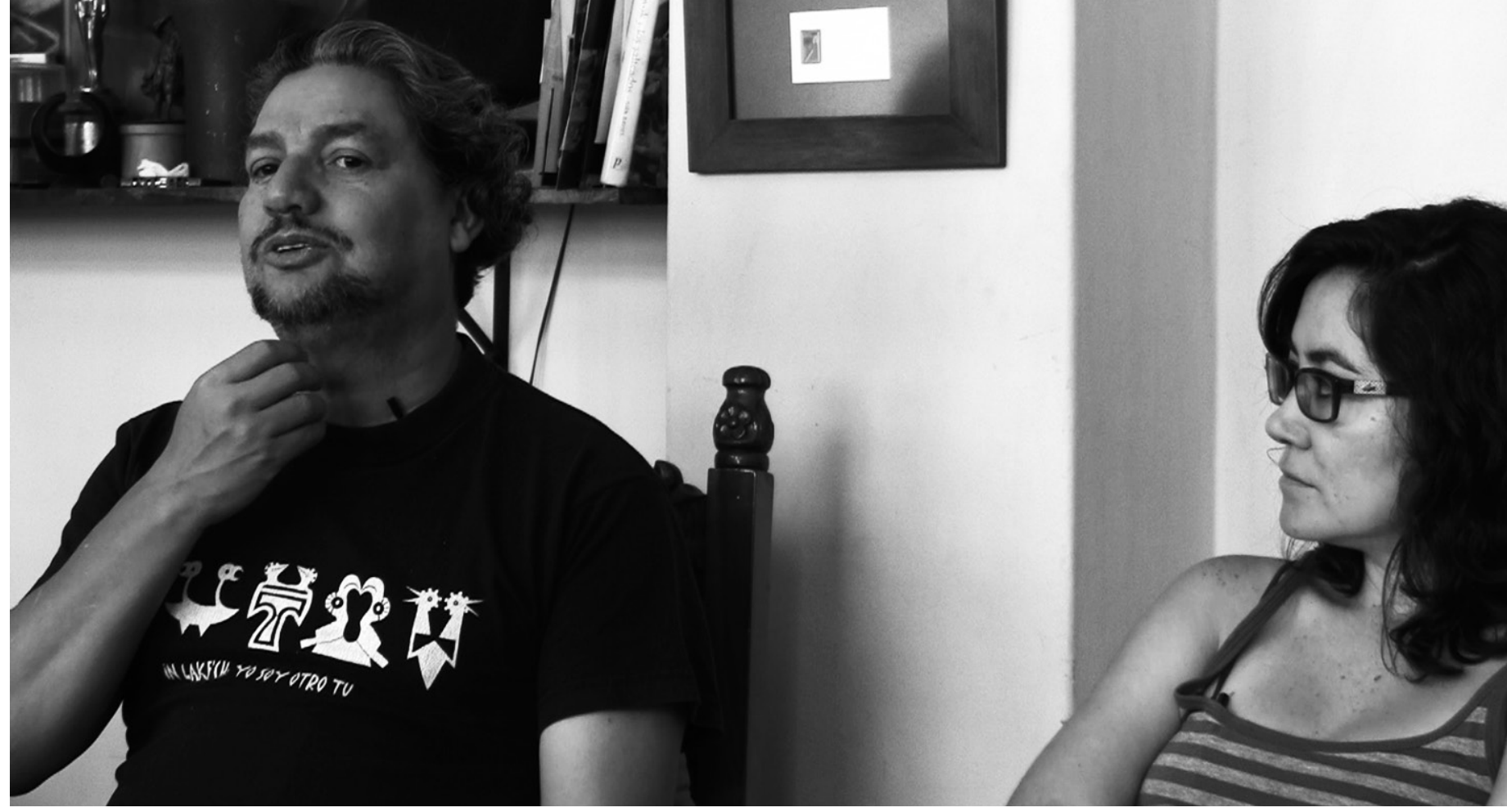

MS: Si puedes decir algo, ¿cómo has visto la creación de programas de comunicación audiovisual en relación con la calidad de la escritura, de las propuestas?

CH: Siento que todavía falta una cosa en las academias, el cine todavía no tiene una valoración importante en su devenir dentro de la historia. No se estudia, no se investiga, no se trabaja una cosa muy importante en la formación de los nuevos realizadores y es la historia, ni la historia del cine mismo, ni siquiera la historia del cine colombiano. Con jóvenes como William Vega, como el chico de La playa, con Ciro Guerra, uno se da cuenta de que hay una generación que tiene una formación académica, que tiene unas estructuras como referentes. Pero en el cine colombiano, como expresión de lo que se hace y aún en la misma formación, necesitamos dar un salto a relacionarnos con mucho más rigor con la investigación, con la historia, con la estética. Eso es lo que va a generar que los jóvenes tengan un criterio propio, que estén ubicados en un contexto que les permita hacer su propio cine.

Aunque también creo que hay otra generación de cineastas, no se trata de satanizarlos, lo veo en alguna gente en Cali, con una visión arribista del cine, buscando la espectacularidad, buscando surgir y meterse en la industria. No es que sea malo estar en la industria, sino que esa visión a veces hace que no generen unos contenidos que, aún siendo cine de género o comercial, conecten con el espectador y que sean interesantes.

Muchas películas que han estado en ese tono de buscar lo comercial fracasan. Y creo que fracasan porque todavía no hay un nivel de calidad dentro de lo que ellos mismos están proponiendo.

MS: En el caso del documental, eso de conocer su historia es mucho más complejo por razones como la dispersión y la circulación limitada de las películas.

CH: Sí, claro. Ahora, creo que el documental colombiano ha estado a la altura de la realidad del país. El documental en Colombia ha permitido visibilizar y expresar la tragedia que vive el país con relación al conflicto armado, no como un asunto sociológico sino de exploración, de visibilizar a los seres humanos que han estado ahí. Hay excelentes documentales que van más allá de lo sociológico, lo antropológico, la denuncia o lo contestatario. Exploran una verdad de lo que en este momento es esa Colombia que no es visible.

Revisado: noviembre 15/ Aprobado: noviembre 28 de 2013 